Check for updates

The BMJ

Cite this as: BMJ 2020;371:m4471 http://dx.doi.org/10.1136/bmj.m4471 Published: 17 November 2020

\title{
Covid-19: Moderna vaccine is nearly $95 \%$ effective, trial involving high risk and elderly people shows
}

\section{Elisabeth Mahase}

The UK government has secured five million doses of the covid-19 vaccine candidate mRNA-1273 from US biotech company Moderna after interim analysis of its phase III trial showed it was $94.5 \%$ effective.

If the vaccine meets standards of safety and effectiveness and is approved by the medicines regulator, the vaccine could be delivered to the UK and Europe as early as spring 2021 with the potential to procure more doses next year, a government statement said.

The trial's Data Safety Monitoring Board-which was appointed by the US National Institute of Health-carried out the analysis based on 95 covid-19 cases, of which 90 were observed in the placebo group and five were reported in the vaccine group.

The trial enrolled more than 30 ooo US participants, including 7000 aged over 65 and 5000 under 65 with high risk chronic diseases. More than one third (37\%) of the trial participants are non-white, with 6000 participants identifying as Hispanic and more than 3000 identifying as black.

Of the 95 cases, 15 were in adults over 65 , and 20 identified as being from diverse communities (12 Hispanic, four black, three Asian American, and one multiracial).

Moderna intends to submit the interim safety and efficacy data to the US Food and Drug Administration (FDA) for emergency use authorisation within the next few weeks, following a final analysis of 151 cases and a median follow-up of more than two months. The trial is being carried out in collaboration with the National Institute of Allergy and Infectious Diseases.

The news comes just over a week after pharmaceutical company Pfizer announced that its covid-19 vaccine candidate was more than $90 \%$ effective, following its interim analysis. ${ }^{1}$ Neither Pfizer nor Moderna have published their full results yet, only releasing information through press releases.

As well as meeting the primary endpoint of the trial (prevention of symptomatic covid-19 disease), the monitoring board looked at the secondary endpoint-prevention of severe disease. There were 11 severe cases of covid-19 reported, all of which occurred in the placebo group.

Professor of experimental medicine at Imperial College London Peter Openshaw, who sits on a Scientific Advisory Group for Emergencies subgroup, said, "This news from is exciting and boosts optimism that we will have a choice of vaccines in the next few months.
"Moderna has announced that the vaccine can be kept in a conventional freezer for up to six months and that once thawed can be kept for up to 30 days in a standard refrigerator. This makes the vaccine much easier to deliver."

Openshaw added that while more details are needed, this announcement "adds to the general feeling of optimism about vaccines for covid-19. What we still don't know is how long any protective immunity may last."

The UK government has so far secured deals for seven vaccine candidates, including Moderna's. A deal has been secured for the Pfizer vaccine, although concerns over logistics have been raised, as it has been reported that it needs to be stored at $-70^{\circ} \mathrm{C}$.

No significant safety concerns for the Moderna vaccine candidate have been reported and a review of solicited adverse events found that the vaccine was generally well tolerated.

Eleanor Riley, professor of immunology and infectious disease at the University of Edinburgh, said, "The safety data also look promising. The side effects of vaccination appear to be in line with those typically seen for other adult vaccinations, including the seasonal influenza vaccination which is administered in many millions of doses every year.

"One important unknown is whether this vaccine, or any of the vaccines currently in trials, prevents disease transmission. It is likely that vaccines that prevent symptomatic disease will reduce the duration and level of infectiousness, and thus reduce transmission, but we don't yet know if this effect will be large enough to make any meaningful difference to the spread of the virus within communities.

"Overall, this is excellent news. Having more than one source of an effective vaccine will increase the global supply and, with luck, help us to get back to something like normal in 2021."

\section{Mahase E. Covid-19: Vaccine candidate may be more than $90 \%$ effective interim results indicate. BMJ2020;371:m4347. doi: 10.1136/bmj.m4347 pmid: 33168562}

This article is made freely available for use in accordance with BMJ's website terms and conditions for the duration of the covid-19 pandemic or until otherwise determined by BMJ. You may use, download and print the article for any lawful, non-commercial purpose (including text and data mining) provided that all copyright notices and trade marks are retained. 